\title{
Intimal Pulmonary Artery Sarcoma Presenting as Severe Dyspnea and Right Heart Insufficiency
}

\author{
Michael Halank $^{\mathrm{a}} \quad$ Christiane Jakob $^{\mathrm{b}} \quad$ Martin Kolditz $^{\mathrm{a}} \quad$ Gerd Hoeffken $^{\mathrm{a}} \quad$ Utz Kappert $^{\mathrm{c}}$ \\ Gerhard Ehninger $^{\mathrm{a}}$ Matthias Weise ${ }^{\mathrm{d}}$ \\ ${ }^{a}$ Medizinische Klinik und Poliklinik I, Universitätsklinikum an der TU Dresden, \\ ${ }^{\mathrm{b}}$ Institut für Pathologie, Universitätsklinikum an der TU Dresden, \\ ${ }^{\mathrm{c}}$ Herzzentrum Dresden, Universitätsklinik, Klinik für Kardiochirurgie, TU Dresden, \\ ${ }^{\mathrm{d}}$ Medizinische Kliniken Arbeitsbereich Intensivstation, Universitätsklinikum an der TU Dresden, Germany
}

\section{Key Words}

Pulmonary artery sarcoma - Right heart insufficiency .

Dyspnea · Echocardiography · Surgery

\section{Summary}

Background: Pulmonary artery sarcoma is a rare tumor with a poor prognosis. Case Report: We report the case of a 64-year-old man with an intimal pulmonary artery sarcoma presenting with severe high oxygen flow-demanding dyspnea and weight loss of $12 \mathrm{~kg}$ in the last 6 months. On echocardiography, right heart insufficiency, markedly elevated right ventricular pressure, a pressure gradient along the right outflow tract, and a tumor mass adherent to the wall of the truncus pulmonalis were detected. The tentative diagnosis by echocardiographic findings was pulmonary artery sarcoma. Computed tomography of the thorax and 18-fluorodeoxyglucose positron emission tomography showed an advanced local tumor manifestation. Surgical resection of the tumor to improve hemodynamics confirmed the diagnosis. Conclusions: Pulmonary artery sarcoma should be considered as a rare differential diagnosis in patients with dyspnea due to right heart failure, particular in the case of additional weight loss, and echocardiographic examination is a useful first diagnostic approach in establishing the diagnosis.

\author{
Schlüsselwörter \\ Pulmonalarteriensarkom - Rechtherzinsuffizienz . \\ Luftnot · Echokardiographie · Operation
}

\section{Zusammenfassung}

Hintergrund: Das Pulmonalarteriensarkom ist eine seltene Erkrankung mit einer schlechten Prognose. Fallbericht: Wir berichten über einen 64-jährigen Mann mit einem intimalen Pulmonalarteriensarkom, der sich mit starker Luftnot trotz hoher Sauerstoffsubstitution und einem Gewichtsverlust von $12 \mathrm{~kg}$ in den letzten 6 Monaten vorstellte. Echokardiographisch fielen eine Rechtsherzinsuffizienz, ein deutlich erhöhter rechtsventrikulärer Druck, ein Druckgradient über dem rechten Ausflusstrakt und eine Tumormasse im Bereich des Trunkus pulmonalis mit Kontakt zur Gefäßwand auf. Die mittels Echokardiographie erhobene Verdachtsdiagnose lautete Pulmonalarteriensarkom. Die Computertomographie des Thorax und die 18-Flur-Desoxyglukose-Positron-Emissionstomographie erbrachten den Befund eines lokal fortgeschrittenen Tumors. Die chirurgische Resektion des Tumors, die zur Verbesserung der Hämodynamik durchgeführt wurde, bestätigte die Diagnose. Schlussfolgerungen: Das Pulmonalarteriensarkom sollte differenzialdiagnostisch als eine seltene Ursache der Luftnot im Rahmen einer Rechtsherzinsuffizienz, insbesondere bei zusätzlichem Gewichtsverlust, in Erwägung gezogen werden. Die Echokardiographie stellt eine wertvolle initiale Untersuchungsmethode bei der Diagnosestellung dar.

\section{KARGER}

Fax +497614520714

Information@Karger.de

www.karger.com (c) 2010 S. Karger GmbH, Freiburg 


\section{Introduction}

Dyspnea is a frequent complaint of patients presenting at the emergency room, and a variety of different diagnoses have to be considered. In the case of echocardiographic signs of pulmonary hypertension, like right heart dilatation, reduced right heart function, and tricuspid insufficiency, a discrimination between acute and chronic conditions like acute pulmonary embolism or idiopathic pulmonary arterial hypertension, respectively, is necessary. Chronic pulmonary hypertension, if assumed by a physician, represents a complex disorder scaled into 5 classes which were updated in 2008 at the 4th World Symposium on Pulmonary Hypertension [1]. Sarcomas arising from the pulmonary artery are a rare cause of right heart insufficiency provoking dyspnea. Here, we report a case of intimal sarcoma, presenting at the emergency room with severe dyspnea and echocardiographic signs of elevated right ventricular pressure and right heart insufficiency.

\section{Case Report}

A 64-year-old Caucasian man presented to the hospital with severe dyspnea at rest despite high-flow oxygen supplementation. He had a history of arterial hypertension and diabetes mellitus type II with consecutive betablocker and metformin therapy. Additionally, progressive dyspnea and weight loss of $12 \mathrm{~kg}$ within the last 6 months were reported. Physical examination revealed a tachypneic and cyanotic patient despite oxygen supplementation with $10 \mathrm{l} / \mathrm{min}$, prominent jugular veins, and a $2 / 6$ systolic murmur at the pulmonic and tricuspid area. Systemic blood pressure was $110 / 70 \mathrm{mmHg}$ and heart rate $120 / \mathrm{min}$. Supine chest X-ray showed no pathologic findings. The laboratory investigation revealed slight anemia (hemoglobin $8.1 \mathrm{mmol} / 1$, normal range $8.6-12.1 \mathrm{mmol} / \mathrm{l}$ ) and moderately elevated C-reactive protein of $40 \mathrm{mg} / 1$ (normal $<5 \mathrm{mg} / \mathrm{l}$ ). Procalcitonin and leukocytes were within the normal range. Creatine kinase and troponin $\mathrm{T}$ were not elevated, and the electrocardiogram (ECG) showed right axis deviation without signs of cardiac ischemia. The serum level of NT-pro brain natriuretic peptide was markedly increased $(670 \mathrm{pmol} / \mathrm{l}$, normal: $<15 \mathrm{pmol} / \mathrm{l})$. Analysis of blood gases revealed moderate hypoxemia $(\mathrm{paO} 2: 7.9 \mathrm{kPa})$ and severe hyperventilation $(\mathrm{pCO} 2: 3.2 \mathrm{kPa}$, pH:7.52) despite oxygen supplementation with $10 \mathrm{l} / \mathrm{min}$. All other laboratory parameters measured were within the normal range. A two-dimensional transthoracic echocardiogram demonstrated normal function and diameters of the left heart and moderate right ventricular dilatation with diffuse hypokinesis and moderately impaired right ventricular pump function. The interventricular septum was flattened during systole and diastole. Also, dilation of the right atrium and displacement of the interatrial septum towards the left atrium were found. Moderate tricuspid regurgitation was detectable by continuous wave Doppler, with a maximal jet velocity of $4.8 \mathrm{~m} / \mathrm{s}$, implying high right ventricular pressure (about $110 \mathrm{mmHg}$ ). Chest computed tomography, performed to determine the reason for the assumed pulmonary hypertension, demonstrated a widespread contrast agent-sparing truncus pulmonalis extending to the left pulmonary artery and a tumor mass surrounding these vessel sections. Also, an infiltration of the left upper lobe and lingula, and prominent left hilar and left pretracheal lymph nodes were seen. Histological examination of tissue gained by transbronchial needle aspiration of the mediastinal and hilar lymph nodes did not display pathologic findings. A wedge excision of the left upper lobe of the lung performed during thoracoscopy showed hemorrhagic pulmonary infarction, but no signs of malignancy.

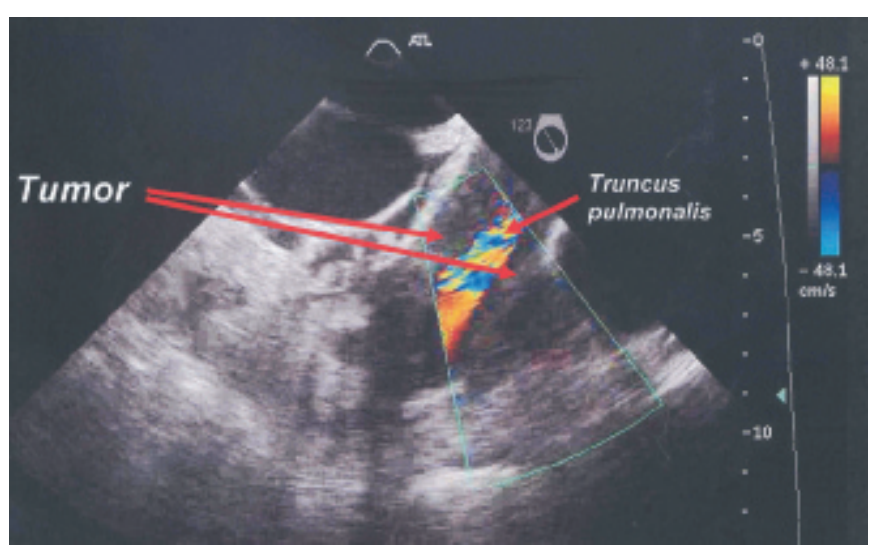

Fig. 1. Transesophageal examination of the truncus pulmonalis by combined brightness mode and color Doppler echocardiography.

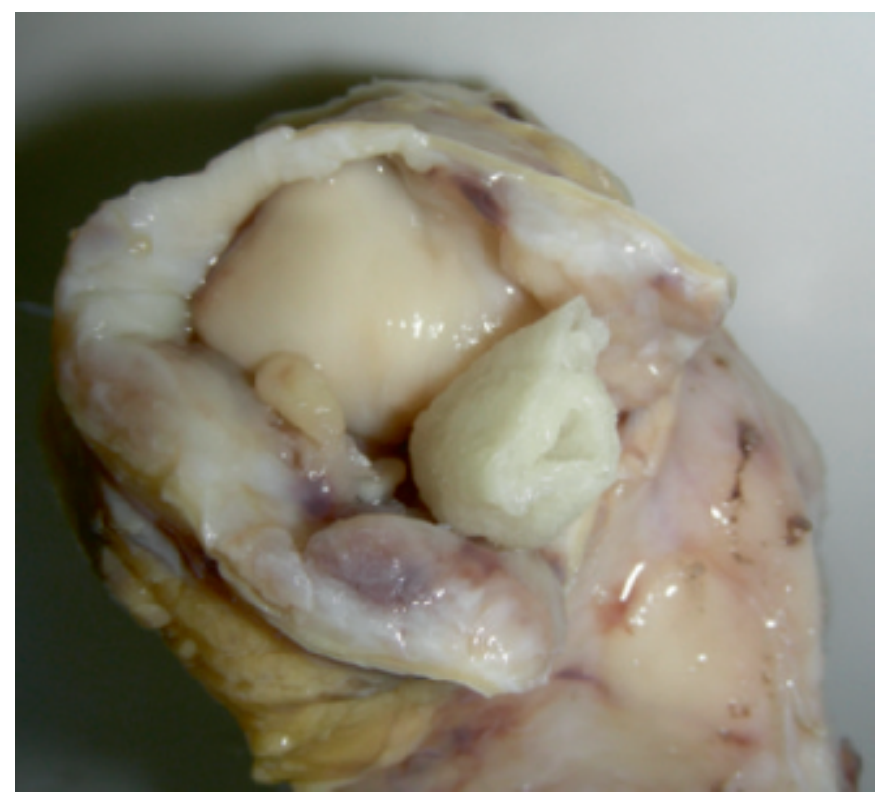

Fig. 2. Truncus pulmonalis after arteriotomy. Sarcoma of the pulmonary artery; the vascular lumen of the truncus pulmonalis is filled with a yellow-gray mucoid and gelatinous mass with a smooth and glossy surface.

Two weeks later, the patient was transferred to our intensive care unit. Repeated transthoracic echocardiography demonstrated progressive signs of right heart insufficiency with the known elevated pressure gradient across the tricuspid valve, but additionally a high pressure gradient $(4.7 \mathrm{~m} / \mathrm{s})$ across the pulmonary valve was measured. Transesophageal echocardiography revealed an intravascular mass adherent to the wall of the truncus pulmonalis and subtotally occluding the lumen of the vessel (fig. 1). We predicted a diagnosis of pulmonary artery sarcoma. 18-fluorodeoxyglucose positron emission tomography of the thorax and abdomen showed intensive pathologically enhanced accumulation in the left paramediastinal region in the area of the right heart (maximum standardized uptake value (SUV): 13.0) and in the mediastinum in the area of the arch of the aorta (SUV: 7.1) with no signs of lymph node or systemic metastasis. Therapeutic options of chemotherapy, surgical resection of the tumor, and radiation were discussed with the patient, oncologists, pneumologists, thoracic and heart surgeons, and critical care physicians. Due to the severe right heart insufficiency in the context of the obstructed pulmonary 


\begin{abstract}
Fig. 3. Left pulmonary artery. a Macroscopic view: pulmonary artery sarcoma; cross section of the left main trunk of the pulmonary artery; intraluminal polypoid growth pattern of the tumor with subtotal obliteration of the vascular lumen. b Microscopic view: intraluminal growth of the pulmonary artery sarcoma; the tumor (upper left) shows proliferation of spindle cells with scant collagenous stroma.
\end{abstract}
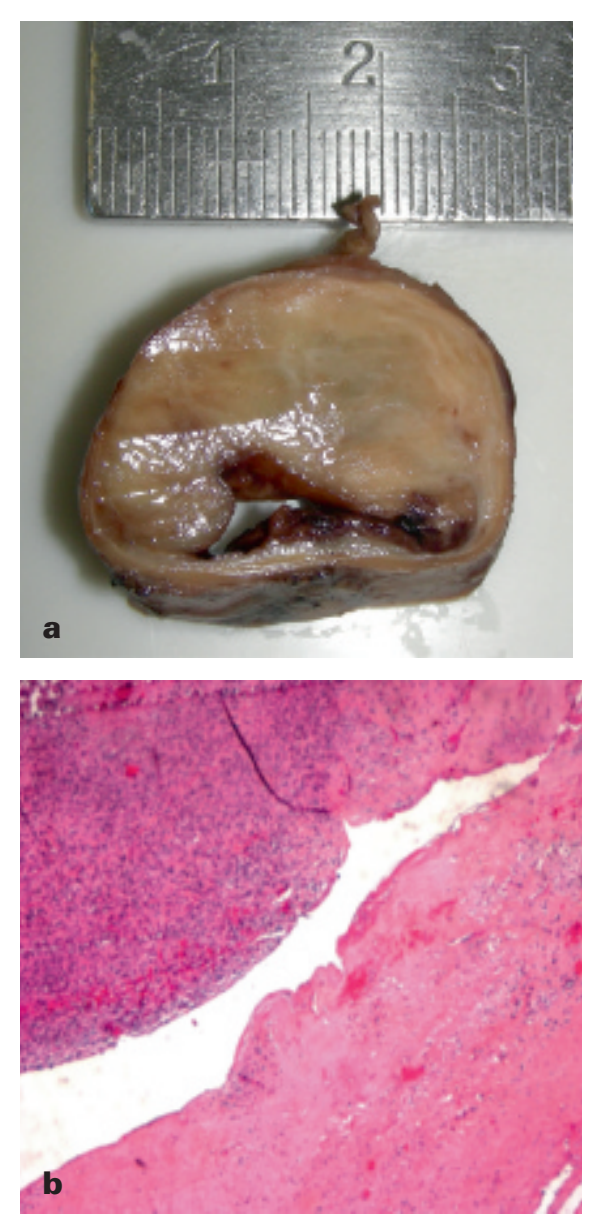

the velocity jets across the tricuspid and pulmonary valves, the initial diagnosis of pulmonary hypertension could be ruled out. Thromboembolism with the consequence of severe right heart insufficiency is associated with pulmonary hypertension. Due to this fact, thromboembolic disease could not be the cause of the intraluminal mass in the truncus pulmonalis [2]. Typical pathologic correlates for a pressure gradient across the right ventricular outflow tract without intraluminal mass are pulmonary valve stenosis and compression of the truncus pulmonalis by an extravascular tumor. In the described case, a pulmonary artery tumor was made probable by both the Doppler pressure gradient in the area of the right outflow tract and by detection of a visible intravascular mass. Thus, the tentative diagnosis of sarcoma of the pulmonary artery had already been made after echocardiographic examination.

Right heart catheterization with invasive confirmation of the pressure gradient, as done by another group in a patient with pulmonary artery sarcoma [3], was not performed in our patient. In their case report, the authors describe the finding of an elevated right ventricular systolic pressure of $95 \mathrm{mmHg}$, but systolic pressures in the right/left pulmonary artery of $15 / 20 \mathrm{mmHg}$, respectively, which lie within the normal range. However, an elevated pressure in the pulmonary artery also might be found due to pulmonary tumor emboli confining the total lumen size of the pulmonary vasculature [4].

Sarcoma of the pulmonary artery is a very rare disease responsible for dyspnea in the context of severe right heart insufficiency. Other frequent complaints are chest pain, cough, and hemoptysis. To date, fewer than 250 cases have been reported in the literature [5]. The World Health Organisation (WHO) classifies sarcomas on the basis of massin-trichrome, hematoxylin-eosin, and periodic acid-Schiff stained sections [6]. Different histopathological patterns in various frequencies of pulmonary sarcomas have been described [2]. Vascular sarcomas are malignant mesenchymal tumors arising, amongst others, in large vessels including the aorta, vena cava, and pulmonary arteries. The defining feature of sarcomas of the great vessels is intraluminal growth with obstruction of the lumen [7]. Sarcomas of the pulmonary artery typically arise from the pulmonary trunk and spread either retrograde into the pulmonary valve or antegrade into pulmonary artery branches. Particularly, as long as the tumor does not spread transmurally into the adjacent lung or lymph nodes, and systemic metastases are not known, misdiagnosis as pulmonary thromboembolism is common [2].

Even though no established treatment regimen exists for pulmonary artery sarcoma due to the rareness of the disease, early radical surgical resection is recommended [5]. Median survival time of patients with diagnosed pulmonary artery sarcoma without surgical intervention is limited to approximately 1.5 months because of progressive right heart failure [8]. An aggressive surgical approach can result in a survival time of 5 years or longer [2, 9]. Even if only incomplete resection can 
be performed, the average survival time in 23 patients was $13.5 \pm 11.7$ months after surgery [10]. Thus, even if cure is unlikely, surgical treatment should be attempted in all patients [7]. However, preoperative severity of right heart failure seems to be a predictor for patient outcome. The role of neoadjuvant or adjuvant chemotherapy or radiation treatment strategies needs to be evaluated. Some reports have shown beneficial effects [7, 11-13]. Anthracycline- and ifosfamidebased chemotherapies are available options [7]. Because of the severe right heart dysfunction with resulting respiratory insufficiency in our patient, neoadjuvant chemotherapy or radiation were not considered.
We conclude that pulmonary artery sarcoma should be considered as a rare differential diagnosis of right heart failure, and that echocardiographic examination including pressure gradient measurement across the right ventricular outflow tract and transesophageal imaging of the pulmonary arteries is a useful first approach in establishing the diagnosis.

\section{Conflict of Interest}

The authors declare no conflict of interest. None of the authors received support by a pharmaceutical or other company.

\section{References}

1 Simonneau G, Robbins IM, Beghetti M, Channick RN, Delcroix M, Denton CP, Elliot CG, Gaine SP, Gladwin MT, Jing Z-C, Krowka MJ, Langleben D, Nakanishi N, Souza R: Updated clinical classification of pulmonary hypertension. J Am Coll Cardiol 2009;54:S43-54

2 Mayer E, Kriegsmann J, Gaumann A, Kauczor HU, Dahm M, Hake U, Schmid FX, Oelert H: Surgical treatment of pulmonary artery sarcoma. J Thorac Cardiovasc Surg 2001;121:77-82.

3 Huwer H, Özbek C, Waldmann R, Winning J, Irsinghaus H, Kalweit G: Sarcoma of the pulmonary trunk and the main arteries. J Surg Oncol 2008;97: 476-478.

4 Pinamonti B, Sinagra G, Slavich G, Calucci F, DePangher Manzini V, Bussani R, Silvestri F: Echocardiographic and Doppler findings in primary sarcoma of the pulmonary artery. Echocardiography 1992;9:155-160.
5 Blackmon SH, Rice DC, Correa AM, Mehran R, Putnam JB, Smythe WR, Walkes J-C, Walsh G,L, Moran C, Singh H, Vaporciyan AA, Reardon M: Management of primary pulmonary artery sarcomas. Ann Thorac Surg 2009;87:977-984.

6 Burke AP, Virmani R: Sarcomas of the great vessels. A clinicopathologic study. Cancer 1993;71: 1761-1773.

7 Mayer F, Aebert H, Rudert M, Königsrainer A, Horger M, Kanz L, Bamberg M, Ziemer G, Hartmann JT: Primary malignant sarcomas of the heart and great vessels in adult patients - a single-center experience. Oncologist 2007;12:1134-1142.

8 Krüger I, Borowski A, Horst M, de Vivie ER, Theissen P, Gross-Fengels W: Symptoms, diagnosis, and therapy of primary sarcomas of the pulmonary artery. Thorac Cardiovasc Surg 1990;38:91-95.

9 Mattoo A, Fedullo PF, Kapelanski D, Ilowite JS: Pulmonary artery sarcoma: a case report of surgical cure and 5-year follow-up. Chest 2002;122:745-747.
10 Tanaka I, Masuda R, Inoue M, Kasahara D, Furuhata Y, Shimizu S, Takemura T: Primary pulmonary-artery sarcoma. Thorac Cardiovasc Surg 1994; 42:64-68.

11 Uchida A, Tabata M, Kiura K, Tanimoto Y, Kanehiro A, Aoe M, Ohohara N, Ueoka H, Tanimoto M: Succesfull treatment of pulmonary artery sarcoma by a two-drug combination chemotherapy consisting of ifosfamide and epirubicin. Jpn J Clin Oncol 2005;35:417-419.

12 Hirose T, Ishikawa N, Hamada K, Inagaki T, Kusumoto S, Shirai T, Okuda K, Ohnishi T, Kadokura M, Adachi M: A case of intimal sarcoma of the pulmonary artery treated with chemotherapy. Intern Med 2009;48:245-249.

13 Genoni M, Biraima AM, Bode B, Shah AC, Wilkler MB, Turina MI: Combined resection and adjuvant therapy improves prognosis of sarcomas of the pulmonary trunk. J Cardiovasc Surg 2001;42:829833. 